\title{
Biological treatment of a contaminated gaseous emission from a leather industry in a suspended-growth bioreactor
}

\author{
M.F. Carvalho, A.F. Duque, S.C. Moura, C.L. Amorim, R.M. Ferreira Jorge, P.M.L. Castro * \\ Escola Superior de Biotecnologia, Universidade Católica Portuguesa, Rua Dr. António Bernardino de Almeida, $4200-072$ Porto, Portugal
}

Keywords:

Biological treatment

Vapour phase bioreactor

Suspended-growth bioreactor

Volatile organic compounds

Gaseous emissions

\begin{abstract}
A B S T R A C T
A suspended-growth bioreactor (SGB) was operated for the treatment of a gaseous stream mimicking emissions generated at a leather industrial company. The main volatile organic compounds (VOCs) present in the gaseous stream consisted of 1-methoxy-2-propanol, 2,6-dimethyl-4-heptanone, 2-butoxyethanol, toluene and butylacetate. A microbial consortium able to degrade these VOCs was successfully enriched. A laboratory-scale SGB was established and operated for 210-d with an $8 \mathrm{~h}$ cycle period and with shutdowns at weekends. Along this period, the SGB was exposed to organic loads (OL) between 6.5 and $2.3 \times 10^{2} \mathrm{gh}^{-1} \mathrm{~m}^{-3}$. Most of the compounds were not detected at the outlet of the SGB. The highest total VOC removal efficiency (RE) (ca 99\%) was observed when an OL of $1.6 \times 10^{2} \mathrm{~g} \mathrm{~h}^{-1} \mathrm{~m}^{-3}$ was fed to the SGB. The maximum total VOC elimination capacity $\left(1.8 \times 10^{2} \mathrm{~g} \mathrm{~h}^{-1} \mathrm{~m}^{-3}\right)$ was achieved when the OL applied to the SGB was $2.3 \times 10^{2} \mathrm{~g} \mathrm{~h}^{-1} \mathrm{~m}^{-3}$. For all the operating conditions, the SGB showed high levels of degradation of toluene and butylacetate ( $R E \approx 100 \%$ ). This study also revealed that recirculation of the gaseous effluent improved the performance of the SGB. Overall, the SGB was shown to be robust, showing high performance after night and weekend shutdown periods.
\end{abstract}

\section{Introduction}

Industrial and manufacturing operations release, on a large scale, volatile organic compounds (VOCs) to the air. VOCs are of significant environmental concern as some contribute to the photochemical ozone creation potential, ozone depletion potential, global warming potential, toxicity, carcinogenicity and local nuisance from odour (BREF, 2003a). These facts led to stricter environmental regulations during the last decade (Council Directives 1999/13/EC and 2004/42/EC).

Treatment of gaseous emissions containing VOCs using conventional technologies, such as activated carbon adsorption, absorption, scrubbing, condensation, thermal and catalytic incineration, present a number of problems, including high cost and little public acceptance (Baltzis, 1998; Rene et al., 2005). Biological systems for the treatment of VOC emissions may represent an advantageous solution as (1) they are natural treatment systems, with lower waste generation; (2) there is lower consumption of energy and chemical supplements; (3) they are well accepted by the public; and (4) they may completely degrade the contaminants into innocuous or lesscontaminating products (Kennes and Thalasso, 1998).

Vapour phase bioreactors (VPBs) offer a natural solution for the treatment of industrial VOC emissions, being regarded as best

\footnotetext{
" Corresponding author. Tel.: +351 225580059; fax: +351225090351.

E-mail address: plcastro@esb.ucp.pt (P. Castro).
}

available technologies (BREF, 2003a,b,c). VPBs have been effectively applied at laboratory scale in the treatment of a wide variety of VOCs (Bastos et al., 2003), including aliphatics (Deshusses et al., 1995; Kirchner et al., 1991), chlorinated aliphatic and aromatics (Speitel and McLay, 1993) and monocyclic aromatics (Smith et al., 1996; Pedersen et al., 1997). Biofilters, bioscrubbers and biotrickling filters are the most commonly used VPBs. Bastos et al., (2003) reported a study on the use of a biotrickling filter that was successfully scaled up and operated in situ for the treatment of gaseous emissions from a paint and varnish industrial plant. Suspended growth bioreactors (SGB) have been recently the subject of study for the treatment of gas streams containing VOCs (Neal and Loehr, 2000; Oliveira and Livingston, 2003), indicating that SGBs can treat gaseous emissions containing VOCs effectively. In an SGB the VOC emission is bubbled into an aqueous suspension of microorganisms, with some potential advantages over immobilised systems, such as absence of plugging and easier biomass and nutrient control (Bielefeldt and Stensel, 1998; Neal and Loehr, 2000).

The treatment of streams highly concentrated in VOCs is known to be one of the major limitations of VPBs. Different strategies have been investigated trying to overcome this limitation, with the most commonly used being the use of buffers, both organic (e.g. silicon oil) and inorganic (e.g. activated carbon), to dampen the high loads (Oliveira and Livingston, 2003). The use of sunflower oil as an organic buffer, placed upstream of a bioscrubber, was shown to have a smoothening effect in the process inlet concentration, 
stabilizing the biotreatment of fluorobenzene (Koutinas et al., 2007). However these strategies have limited efficiency due to the saturation of the buffer when exposed to highly concentrated continuous streams. Gas recirculation may overcome this limitation by increasing the gas - liquid contact time inside the SGB thus improving the mass-transfer process.

The objective of this study was to evaluate the performance of an SGB when treating a synthetic gaseous emission mimicking that of a leather industry. The research carried out involved enrichment of VOC degrading microbial cultures, and operation of an SGB mimicking in situ conditions. The effects of inlet organic loading, over-night and weekend shutdowns, starvation periods and gas recycling on the overall treatment performance of the SGB were investigated.

\section{Materials and methods}

\section{Microbial enrichment}

Samples collected from a municipal wastewater treatment plant receiving effluents produced by various leather industries, located in the centre region of Portugal (Alcanena), were used as inocula for the enrichments.

The microbial enrichments targeted the VOCs arising in gaseous emissions from a leather industry. Two main products, a solvent based product and an aqueous based product, are used in the production process and can contribute to the VOC gaseous emissions. Information obtained on these two products indicated that the solvent based product consisted of a cream liquid mixture constituted mainly by butylacetate, silicon, nitrocellulose, ethyl glycol and mineral oils and the aqueous based product consisted of a black liquid mixture constituted mainly by pigments, silica, wax, polyurethane resin, acrylic resin and cellulosic esther.

Microbial enrichments on the solvent based product were established by using the samples mentioned above, previously centrifuged and resuspended in a mineral salts medium (MM) (Caldeira et al., 1999). $250 \mathrm{~mL}$ flasks containing $100 \mathrm{~mL}$ of MM were inoculated with a $10 \%$ inoculum and supplemented with $10 \mu \mathrm{L}$ of the solvent based product, as the sole carbon and energy source. Cultures were incubated on a rotary shaker at $100 \mathrm{rpm}$. One third of the suspension was removed and replaced with fresh medium at 10-d intervals. Growth was monitored by measuring the opti- cal density at $600 \mathrm{~nm}$. For the enrichments on the aqueous based product, a volatilisation strategy was employed. This consisted of bubbling a saturation vessel containing the aqueous based product with a filtered air stream. The outlet of the saturation vessel was connected to a second saturation vessel containing MM and the inoculum above described (in the proportion 3:1, respectively), such that the outlet gas stream of the first saturation vessel, carrying the VOCs resultant from the volatilisation of the aqueous based product, bubbled into the second one (containing the MM plus the inoculum). Growth was periodically monitored in the second saturation vessel by measuring the optical density at $600 \mathrm{~nm}$. All the enrichments were carried out at room temperature under non-sterile conditions.

\section{SGB operation}

The SGB consisted of a stirred tank bioreactor with a working volume of $1.5 \mathrm{~L}$ (Braun Biotech, Germany), operated in a continuous mode, at room temperature, $\mathrm{pH} 7$ and with a stirring speed of $300 \mathrm{rpm}$. The experimental set up is schematically shown in Fig. 1. The SGB was inoculated with $200 \mathrm{~mL}$ of the microbial consortium enriched with the aqueous based product, having a biomass concentration of $0.18 \mathrm{~g} \mathrm{~L}^{-1}$ (in a working volume of $1.5 \mathrm{~L}$ ). Throughout the experiments, the SGB was continuously fed with MM, at a flow rate of $20 \mathrm{mLh}^{-1}$, and with a gaseous stream, which was generated by the controlled vaporisation of the aqueous and/or solvent based products. The required inlet VOC concentrations were obtained through the controlled mixture of the aqueous and/ or solvent based products-laden stream(s) with a gaseous stream previously humidified by the use of independent gaseous massflow controllers (Hastings, UK). By changing the ratio of these streams, different VOC concentrations were fed to the SGB. The proportion between the streams of the aqueous and the solvent based products was that typically found in industry, i.e., 95\% and 5\%, respectively. Experiments were carried out at different organic loads (OLs) and with or without recycling of the outlet gaseous stream. Recycled gas was re-introduced into the reactor through a vacuum pump (Büchi, Germany) supplying half of the feed flow rate. The SGB was operated with a daily $8 \mathrm{~h}$ cycle period and with shutdowns at weekends. The operating conditions tested in the SGB are summarized in Table 1. Initially, the SGB was fed only with a humidified aqueous based product-laden stream. From day 94 ,

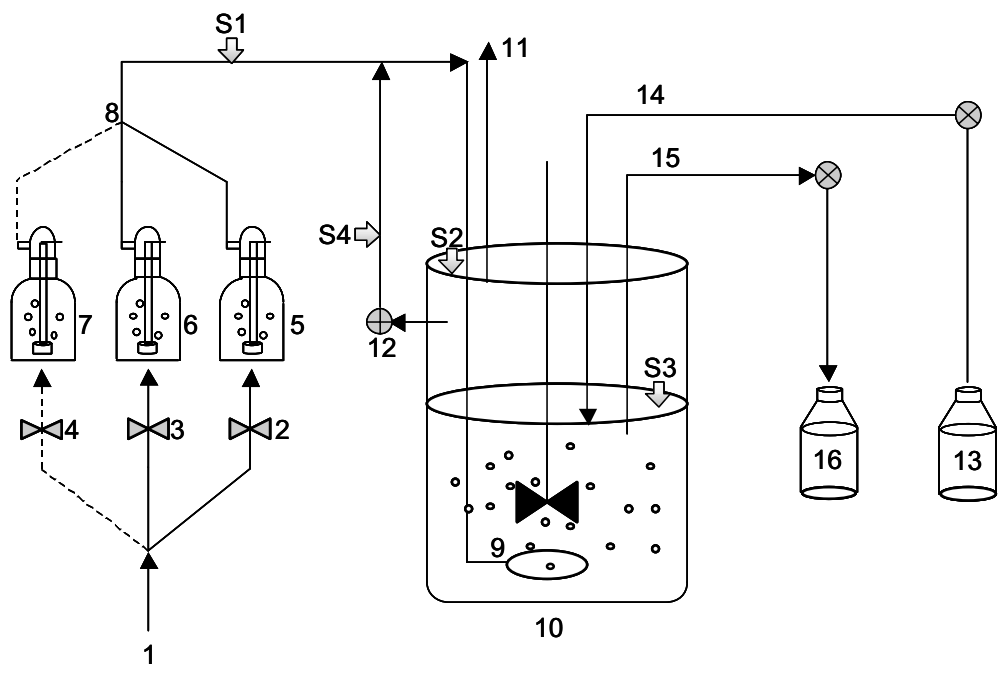

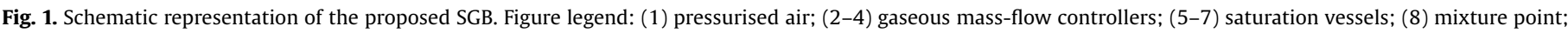

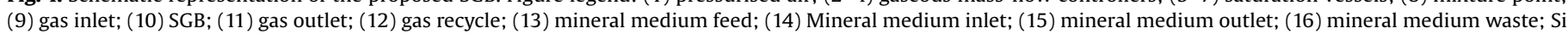
$(i=1-4)$ - sampling points. 
Table 1

Operating conditions tested in the suspended-growth bioreactor

\begin{tabular}{|c|c|c|c|c|c|c|c|c|}
\hline \multirow[t]{2}{*}{ Phase } & \multirow[t]{2}{*}{$\begin{array}{l}\text { Length of } \\
\text { operation (days) }\end{array}$} & \multirow[t]{2}{*}{$\begin{array}{l}\text { Days of } \\
\text { operation }\end{array}$} & \multicolumn{3}{|c|}{$\begin{array}{l}\text { Gas flow }\left(\mathrm{L} \mathrm{min}^{-1}\right) \text { in the saturation vessels } \\
\text { containing }\end{array}$} & \multirow[t]{2}{*}{$\begin{array}{l}\text { Gas recirculated } \\
\left(\mathrm{Lmin}^{-1}\right)\end{array}$} & \multirow[t]{2}{*}{$\mathrm{RT}^{\mathrm{a}}(\mathrm{h})$} & \multirow[t]{2}{*}{ Inlet total VOC Concentration ${ }^{\mathrm{b}}\left(\mathrm{g} \mathrm{m}^{-3}\right)$} \\
\hline & & & Water & $\begin{array}{l}\text { Aqueous based } \\
\text { product }\end{array}$ & $\begin{array}{l}\text { Solvent based } \\
\text { product }\end{array}$ & & & \\
\hline I & $0-19$ & 19 & 1.95 & 0.05 & 0.00 & 0.00 & 0.013 & $0.24 \pm 0.02$ \\
\hline II & $20-24$ & 4 & 1.95 & 0.05 & 0.00 & 1.00 & 0.013 & $0.23 \pm 0.03$ \\
\hline III & $25-33$ & 8 & 1.50 & 0.50 & 0.00 & 0.00 & 0.013 & $0.47 \pm 0.05$ \\
\hline IV & $34-41$ & 7 & 1.50 & 0.50 & 0.00 & 1.00 & 0.013 & $0.35 \pm 0.10$ \\
\hline V & $42-51$ & 9 & 1.50 & 0.50 & 0.00 & 0.00 & 0.013 & $0.26 \pm 0.01$ \\
\hline VI & $52-60$ & 8 & 0.25 & 0.25 & 0.00 & 0.00 & 0.050 & $0.50 \pm 0.04$ \\
\hline VII & $61-65$ & 4 & 0.25 & 0.25 & 0.00 & 0.25 & 0.050 & $0.39 \pm 0.03$ \\
\hline VIIII $^{\mathrm{c}}$ & $66-77$ & 11 & \multicolumn{3}{|c|}{ Starvation period } & & & \\
\hline IX & $78-84$ & 6 & 0.25 & 0.25 & 0 & 0.00 & 0.050 & $0.32 \pm 0.01$ \\
\hline $\mathrm{X}$ & 85-93 & 8 & 0.25 & 0.25 & 0 & 0.25 & 0.050 & $0.39 \pm 0.02$ \\
\hline XI & $94-105$ & 11 & 0.20 & 0.28 & 0.02 & 0.00 & 0.050 & $1.6 \pm 0.13$ \\
\hline XII & $106-114$ & 8 & 0.20 & 0.28 & 0.02 & 0.25 & 0.050 & $1.4 \pm 0.05$ \\
\hline $\mathrm{XIII}^{\mathrm{c}}$ & $115-125$ & 10 & \multicolumn{3}{|c|}{ Starvation period } & & & \\
\hline XIV & $126-137$ & 11 & 0.00 & 0.47 & 0.03 & 0.00 & 0.050 & $0.74 \pm 0.06$ \\
\hline XV & $138-143$ & 5 & 0.00 & 0.47 & 0.03 & 0.50 & 0.050 & $1.9 \pm 0.02$ \\
\hline XVI & $144-151$ & 7 & 0.00 & 0.95 & 0.05 & 0.00 & 0.025 & $0.9 \pm 0.07$ \\
\hline $\mathrm{XVII}^{\mathrm{c}}$ & $152-163$ & 11 & \multicolumn{3}{|c|}{ Starvation period } & & & \\
\hline XVIII & $164-170$ & 6 & 0.00 & 0.95 & 0.05 & 0.50 & 0.025 & $4.1 \pm 0.23$ \\
\hline XIX & $171-184$ & 13 & 0.00 & 1.90 & 0.10 & 0.00 & 0.013 & $2.1 \pm 0.18$ \\
\hline $\mathrm{XX}$ & $185-197$ & 12 & 0.00 & 1.90 & 0.10 & 1.00 & 0.013 & $2.9 \pm 0.10$ \\
\hline $\mathrm{XXI}^{\mathrm{c}}$ & $198-210$ & 12 & 0.00 & 1.90 & 0.10 & 0.00 & 0.013 & $1.6 \pm 0.05$ \\
\hline
\end{tabular}

a RT-Residence time.

b The values listed are means \pm SEM.

c Feeding of mineral salts medium was stopped in these phases.

the bioreactor was fed by volatilising both the aqueous and solvent based products.

\section{Sampling and analyses}

The SGB was monitored for degradation of each of the individual VOC, at four sampling points (Fig. 1). Samples were taken at the gas feed (S1), at the gas outlet (S2) and from the reactor medium (S3). When gas recycling was introduced, the levels of individual VOC were also monitored at the recycled stream (S4). Biomass growth was monitored from samples collected from the reactor medium. $\mathrm{pH}$ and dissolved oxygen (DO) concentration were monitored throughout the experiments. pH was maintained between 6.5 and 7.5. DO was monitored using an oxygen probe (WTW, UK) and was maintained at values higher than $3.5 \mathrm{mg} \mathrm{L}^{-1}$ throughout the experiments.

VOC quantification was carried out using Gas Chromatography (GC) on a Varian Star 3400 CX model using a CP-Wax 52 CB capillary column (Chrompack International B.V., Middelburg, The Netherlands), under a temperature regimen starting at $50^{\circ} \mathrm{C}$ for $2 \mathrm{~min}$, increasing to $150^{\circ} \mathrm{C}$ at a rate of $25^{\circ} \mathrm{Cmin}^{-1}$ and reaching a final temperature of $250^{\circ} \mathrm{C}$ at a rate of $50{ }^{\circ} \mathrm{Cmin}^{-1}$. Liquid samples from the reactor were analysed by extracting a volume of $4.5 \mathrm{~mL}$ with $2 \mathrm{~mL}$ of diethylether containing mesitylene as internal standard. After mixing for $1 \mathrm{~min}$, the ether layer was analysed by split injection of $1 \mu \mathrm{L}$ in the GC. Gas samples were directly analysed by split injection of $0.5 \mathrm{~mL}$ in the GC. VOC concentrations in both liquid and gas samples were calculated from previously prepared calibration curves. Biomass growth was monitored by spectrophotometric measurement at $600 \mathrm{~nm}$ and biomass concentrations were determined using a previously established dry-weight calibration curve.

\section{Reagents}

All chemicals were of the highest purity grade available (Sigma-Aldrich Chemie, Steinheim, Germany; Merck, Darmstadt, Germany).
Results and discussion

Identification of the main VOCs derived from the solvent and aqueous based products

The VOC composition of the solvent and aqueous based products was analysed by GC. Both liquid and gaseous samples of each product were analysed. The major VOCs derived from the solvent based product were identified as toluene and butylacetate, with toluene being present at a slightly higher proportion than butylacetate. The main VOCs resultant from the aqueous based product were identified as 1-metoxy-2-propanol, 2,6-dimethyl-4-heptanone and 2-butoxyethanol, with 1-metoxy-2-propanol being present in a much higher proportion than the two other compounds.

\section{Isolation of cultures capable to degrade the solvent based product}

A microbial consortium capable to degrade the solvent based product was isolated after $3 \mathrm{wk}$ of selective batch enrichments. The consortium was able to grow on and degrade the solvent based product when it was supplied as the sole carbon and energy source. Biodegradation was detected through visible microbial growth and by GC analysis, which showed the disappearance of the main VOCs derived from the solvent based product. This microbial consortium was not, however, able to grow on the aqueous based product.

Isolation of cultures capables to degrade the aqueous based product

An enrichment approach similar to the one used with the solvent based product failed in obtaining microbial cultures capable of degrading the aqueous based product. This was probably due to the presence of toxic compound(s), such like pigments or heavy metals. A volatilisation strategy was then tested, which consisted of enriching microbial cultures by feeding them with a gaseous stream containing the VOCs derived from the volatilisation of the aqueous based product. By using this strategy, a microbial 
consortium was enriched after $2 \mathrm{wk}$. Biodegradation was detected through visible microbial growth and by GC analysis, which showed no VOC accumulation in the microbial culture, indicating that the microorganisms were growing while degrading the VOCs derived from the aqueous based product. In control experiments, with no bacterial inoculum, accumulation of VOCs in the MM was observed.

The capacity of the enriched microbial consortium to biodegrade each of the main VOCs that constitute the aqueous based product, i.e., 1-methoxy-2-propanol, 2,6-dimethyl-4-heptanone and 2-butoxyethanol, as sole carbon sources, was also tested in order to check if any of these compounds could constitute a limiting step in the biodegradation of this product. The three VOC, supplied at a concentration of ca. $4 \mathrm{mM}$ each, were biodegraded within 25-30h (data not shown), showing the capacity of the enriched microbial consortium to biodegrade these compounds. However, the biomass concentration obtained with 1-methoxy-2-propanol was lower than that obtained with 2,6-dimethyl-4-heptanone and 2-butoxyethanol, indicating that the enriched microbial consortium grows more efficiently in the last two compounds.
The enriched microbial consortium showed to be able to grow on and degrade not only the volatilised aqueous based product, but also the solvent based product, either in liquid and gaseous forms (data not shown). Therefore, this microbial consortium was used as inoculum for the SGB experiments.

\section{SGB performance}

A SGB was operated in order to assess its performance when treating a gaseous emission containing the main VOCs emitted from a leather industry and to evaluate the effect of gas recycling on the bioreactor treatment efficiency. Several operating scenarios, divided in XXI different phases, were tested in the SGB (Table 1). The overall operational performance of the SGB is shown in Figs. 2 and 3.

Throughout operation, the VOC concentrations at the outlet of the SGB were, for most of the compounds, very close to zero or, in some cases, below the detection limit (Fig. 2). During the first ten phases (I-X), the bioreactor was fed with a synthetic gaseous stream containing water and only the aqueous based product.

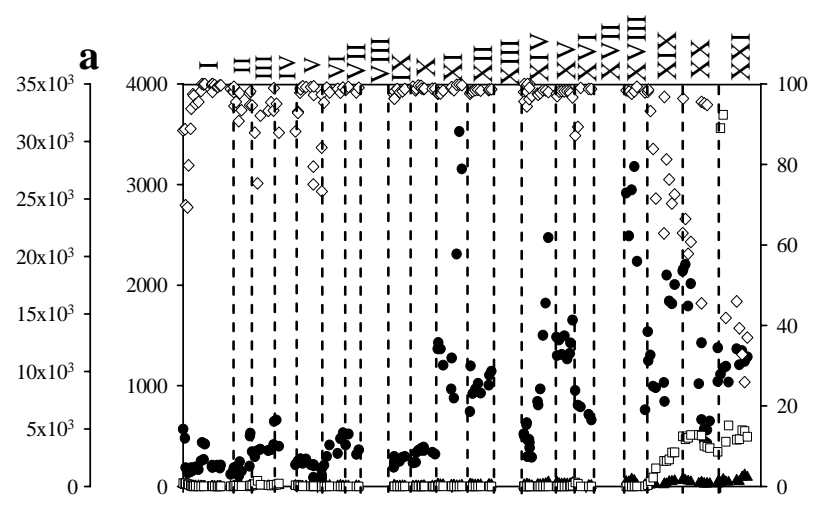

b

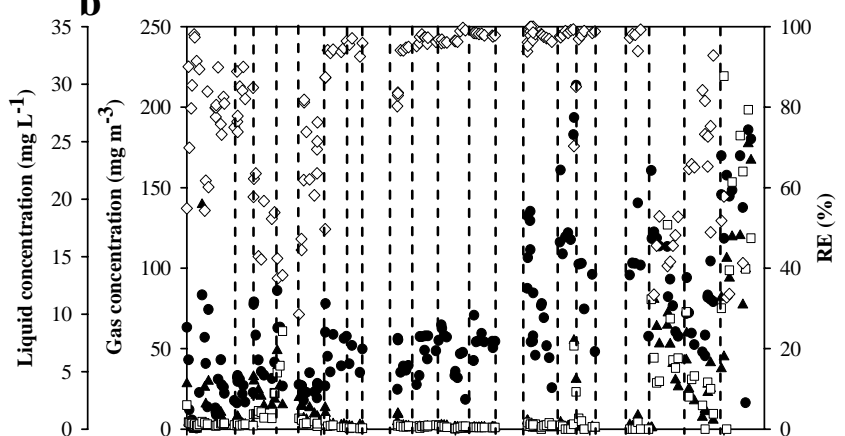

C

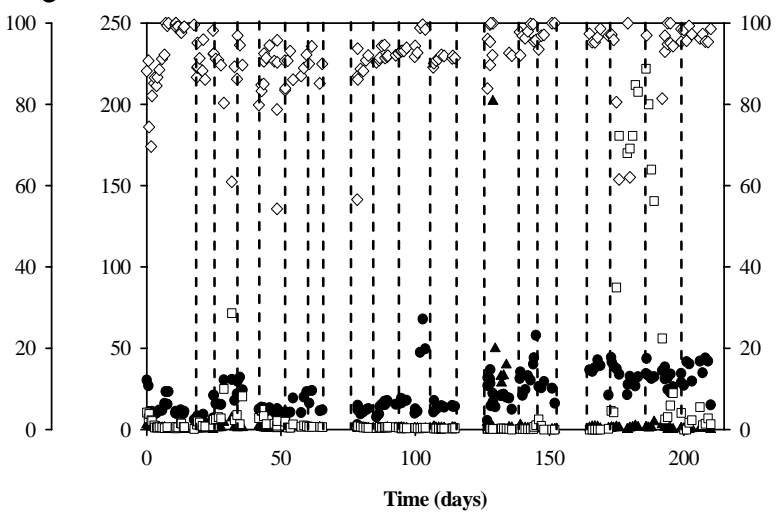

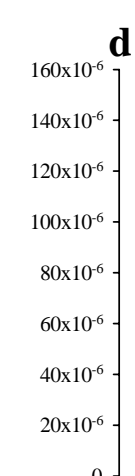
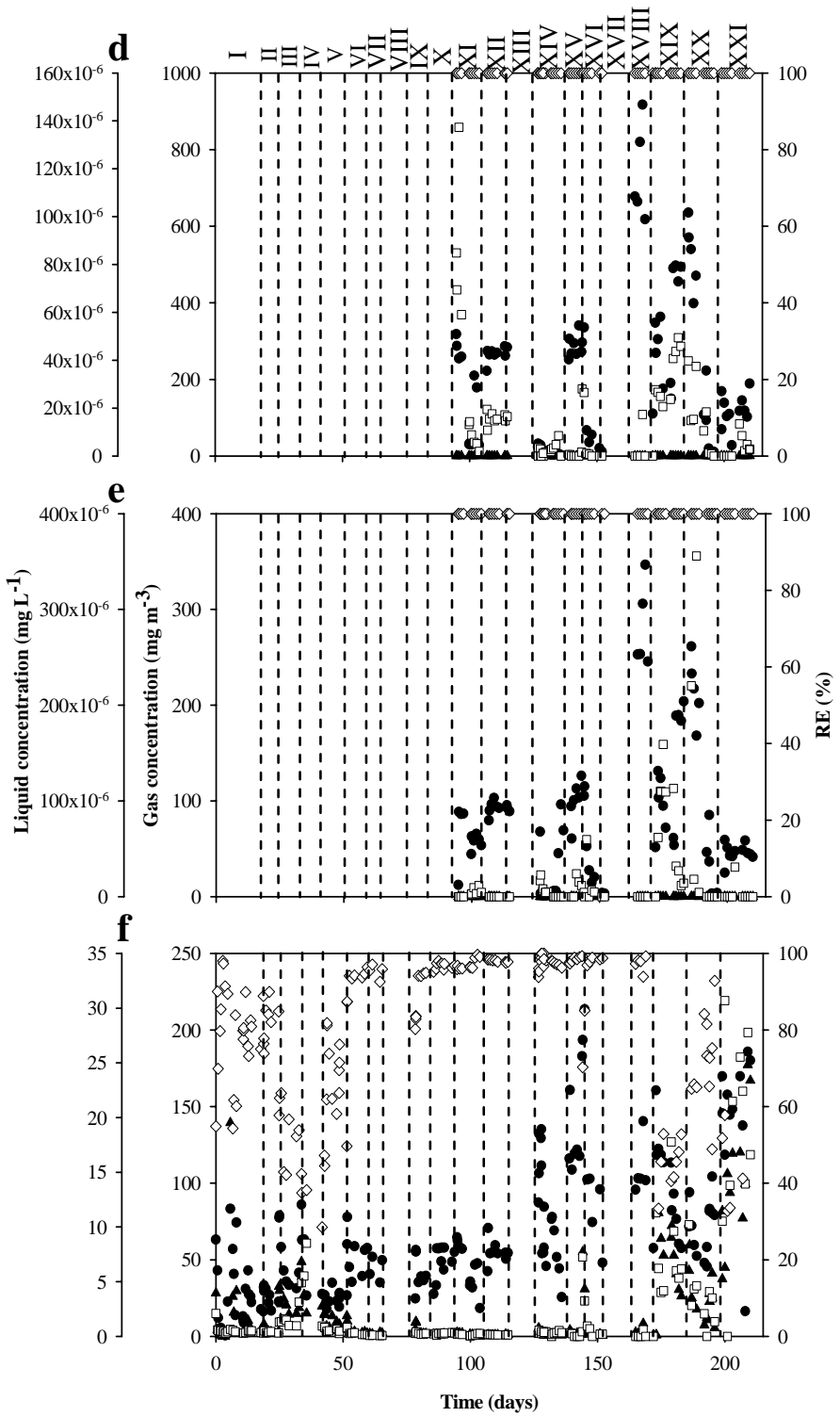

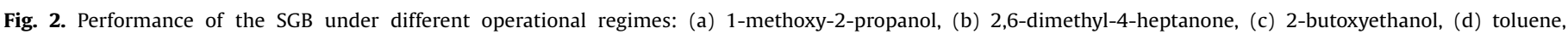
(e) butylacetate and (f) total VOC. Gas concentration (inlet - $\mathbf{0}$; outlet - $\boldsymbol{\Delta}$ ), liquid concentration ( $\square$ ) and removal efficiency (RE - $\diamond$ ) are indicated. 
a 180
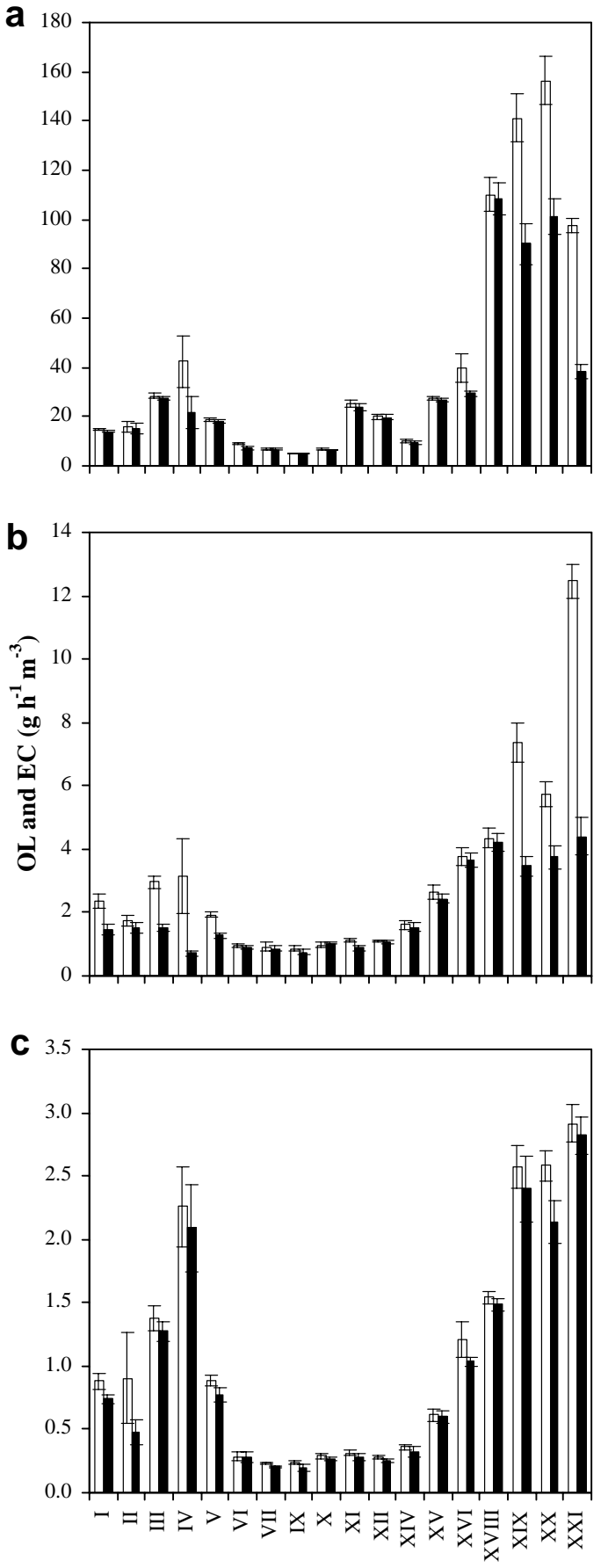

d
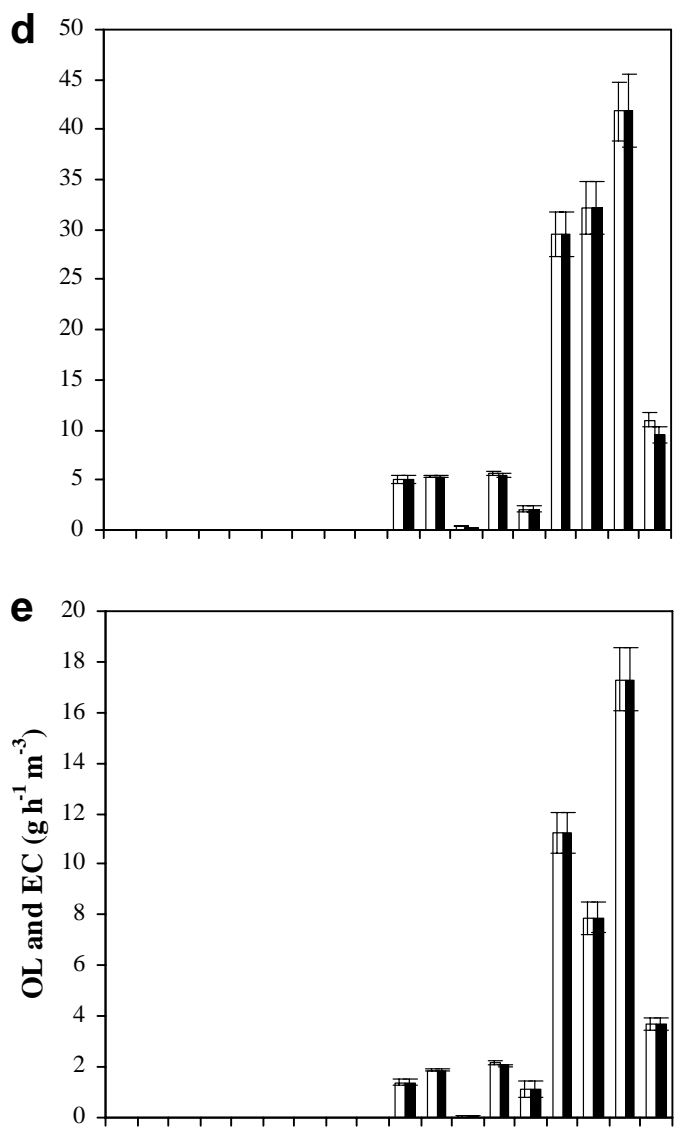

f

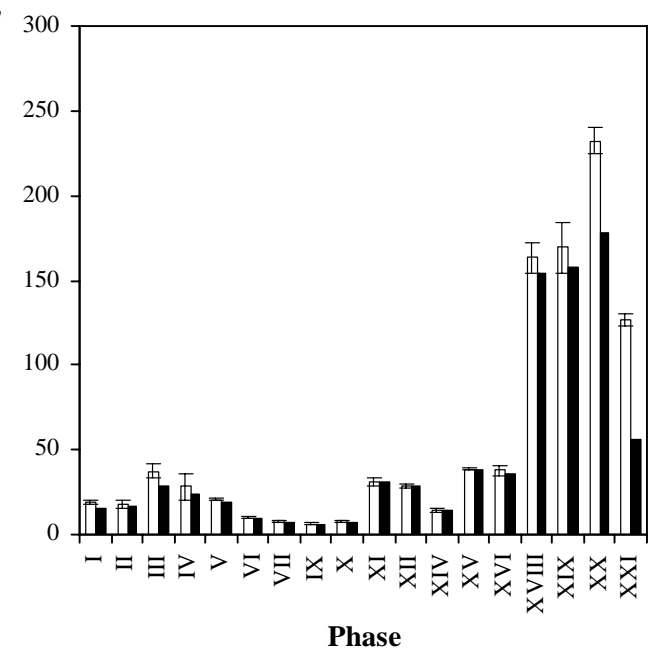

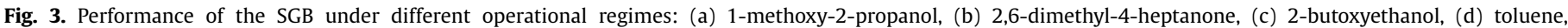
(e) butylacetate and (f) total VOC. Organic load (OL - white bars) and elimination capacity (EC - black bars) are indicated.

The SGB was initially exposed to a gas stream containing a total VOC OL of ca. $19 \mathrm{gh}^{-1} \mathrm{~m}^{-3}$ (phase I), with a residence time (RT) of $0.013 \mathrm{~h}$. Under these circumstances, the SGB showed high removal efficiency (RE), 91\%, and a corresponding elimination capacity (EC) of $16 \mathrm{~g} \mathrm{~h}^{-1} \mathrm{~m}^{-3}$. During phase II, gas recirculation of the outlet gaseous stream was initiated. An overall increase in individual and total VOC RE and EC values were observed along this phase (Figs. 2 and 3). Total VOC RE of $95 \%$ and an EC of $17 \mathrm{~g} \mathrm{~h}^{-1} \mathrm{~m}^{-3}$ were observed, suggesting that the recirculation improved the treatment process. From phases III to V, the SGB was exposed to an aqueous based product gas flow rate ten times higher than that in the previous two phases, reaching $0.5 \mathrm{Lmin}^{-1}$. Despite the overall increase in the EC observed for both total and individual VOC during phase III, the RE immediately decreased, indicating a limitation of the SGB to deal with the OL applied $\left(38 \mathrm{~g} \mathrm{~h}^{-1} \mathrm{~m}^{-3}\right)$. When recirculation of the outlet gas was introduced (phase IV), the RE was maintained, while total VOC EC was lower $\left(24 \mathrm{~g} \mathrm{~h}^{-1} \mathrm{~m}^{-3}\right)$, which was due to the fact that the OL applied during phase IV had also decreased $\left(28 \mathrm{~g} \mathrm{~h}^{-1} \mathrm{~m}^{-3}\right)$. The lower RE and EC in phases III and IV, in comparison to phase II, seems to be due to the fact that both the $\mathrm{RE}$ and EC observed for the compound 2,6-dimethyl-4-heptanone were particularly low during these phases (Figs. $2 \mathrm{~b}$ and $3 \mathrm{~b}$ ), indicating a limitation in the biodegradation of this compound by the microbial population resident in the SGB. In phase V, the decrease 
in the total VOC OL applied to the SGB (to $21 \mathrm{~g} \mathrm{~h}^{-1} \mathrm{~m}^{-3}$ ) resulted in an improvement in the RE of total VOCs (from $83 \%$ to $94 \%$ ) and, in particular, of 2,6-dimethyl-4-heptanone.

From phases VI to $\mathrm{X}$, the total gas flow applied to the bioreactor was reduced from 2 to $0.5 \mathrm{~L} \mathrm{~min}^{-1}$. In these phases, the gas flow rate of the aqueous based product was also reduced to a value of $0.25 \mathrm{Lmin}^{-1}$, resulting in an increase of the RT to $0.05 \mathrm{~h}$. During phase VI, the OL reaching the SGB was $10 \mathrm{~g} \mathrm{~h}^{-1} \mathrm{~m}^{-3}$. Under these circumstances, the bioreactor showed a high RE, 97\%, with an EC of $10 \mathrm{~g} \mathrm{~h}^{-1} \mathrm{~m}^{-3}$. During phase VII, when gas recirculation was introduced, the RE of total and individual VOC was again high - 98\% -which was again reflected in an EC similar to the OL applied.

On phase VIII, the SGB was exposed to a starvation period of 11-d, in order to mimic a periodical plant shutdown. The feed was then re-establish at day 78 (phase IX), with an OL of $6.0 \mathrm{~g} \mathrm{~h}^{-1} \mathrm{~m}^{-3}$. A small decrease in the overall RE was observed (from 98\% to 96\%) and the EC obtained was ca. $6.0 \mathrm{~g} \mathrm{~h}^{-1} \mathrm{~m}^{-3}$, suggesting that the microbial culture resident in the SGB was kept active during the starvation period, probably through interactions among the microbial community (Goodal et al., 1998; Ferreira Jorge and Livingston, 2000a,b). During phase X, when gas recirculation was applied to the SGB, the bioreactor totally recovered its performance with total VOC RE and EC values of $98 \%$ and $8 \mathrm{~g} \mathrm{~h}^{-1} \mathrm{~m}^{-3}$, respectively.

From phase XI the reactor was additionally fed with the solvent based product. During phase XI, REs higher than 95\% were achieved for both individual and total VOCs. On phase XII, gas recirculation of the outlet gaseous stream was introduced to the SGB. The total VOC OL applied in this phase was $29 \mathrm{~g} \mathrm{~h}^{-1} \mathrm{~m}^{-3}$. Under these circumstances, the SGB maintained the high performance, with overall $\mathrm{RE}$ and EC values of $99 \%$ and $28 \mathrm{~g} \mathrm{~h}^{-1} \mathrm{~m}^{-3}$, respectively.

In phase XIII, the SGB was again exposed to another starvation period. After this phase, the SGB was fed with a synthetic gaseous stream containing only the aqueous and solvent based products, with no volatilization of water.

An OL of $15 \mathrm{~g} \mathrm{~h}^{-1} \mathrm{~m}^{-3}$ was fed to the reactor during phase XIV, resulting in a total VOC RE and EC of around $94 \%$ and $14 \mathrm{~g} \mathrm{~h}^{-1} \mathrm{~m}^{-3}$, respectively. When the recirculation of the outlet gas stream was re-introduced (phase $\mathrm{XV}$ ), an improvement in the RE and EC was observed (to $98 \%$ and $38 \mathrm{~g} \mathrm{~h}^{-1} \mathrm{~m}^{-3}$, respectively).

On phase XVI, the total gas flow rate applied to the bioreactor was increased to $1 \mathrm{Lmin}^{-1}$, resulting in a decrease of the RT to $0.025 \mathrm{~h}$. A slight decrease in the RE and in the EC was observed during this phase (Fig. 2). During phase XVII, the SGB was exposed, for 11-d, to another starvation period. After this period, the gas feed was re-established to the bioreactor with an inlet gas flow rate of $1.0 \mathrm{~L} \mathrm{~min}^{-1}$, and the recirculation of the outlet gas stream was introduced (phase XVIII). In spite of the high OL applied to the SGB during this phase $\left(1.6 \times 10^{2} \mathrm{~g} \mathrm{~h}^{-1} \mathrm{~m}^{-3}\right)$, the SGB showed a high RE, of ca $99 \%$, and an EC of $1.6 \times 10^{2} \mathrm{~g} \mathrm{~h}^{-1} \mathrm{~m}^{-3}$, again indicating that the SGB microbial culture was kept active during the starvation period and that the recirculation of the outlet gaseous stream improved the extent of biodegradation of the VOC.

From phase XIX, the total inlet gas flow rate was again increased to a value of $2 \mathrm{~L} \mathrm{~min}^{-1}$ and the aqueous and solvent based products flow rates were increased to 1.9 and $0.1 \mathrm{~L} \mathrm{~min}^{-1}$, respectively, leading to a decrease of the RT to $0.013 \mathrm{~h}$. An OL of $1.7 \times 10^{2} \mathrm{~g} \mathrm{~h}^{-1} \mathrm{~m}^{-3}$ was fed to the SGB during phase XIX. A significant decrease in the RE for most individual VOC and for total VOC was observed, indicating that the bioreactor was not able to deal with the applied operating conditions. On phase XX, gas recirculation was introduced to the SGB. The total VOC OL applied during this phase increased to a value of $2.3 \times 10^{2} \mathrm{~g} \mathrm{~h}^{-1} \mathrm{~m}^{-3}$. These conditions led to a decrease on the RE of individual and total VOC, except for toluene and butylacetate, for which no influence in the biodegradation was observed (Figs. 2 and 3), while the total VOC EC increased to $1.8 \times 10^{2} \mathrm{~g} \mathrm{~h}^{-1} \mathrm{~m}^{-3}$. Even when the OL decreased in phase XXI (to $1.3 \times 10^{2} \mathrm{~g} \mathrm{~h}^{-1} \mathrm{~m}^{-3}$ ), the system was still not able to effectively respond, as the RE and EC obtained were low. This could be partly due to the fact that during this phase the feeding of the mineral salts medium to the SGB was stopped, which may have contributed to the observed higher VOC accumulation in the liquid medium.

The results obtained in the last three operating phases indicated a failure of the SGB to deal with the high OLs and low RTs applied. For all individual VOC, the outlet gas concentrations as well as the liquid concentrations also increased during these last three phases (Fig. 2), indicating that the higher VOC concentrations fed to the bioreactor during these phases might have an inhibitory effect in the microbial population. During a study on the effects of gas flow rate and inlet concentration in the biofiltration of xylene, Jorio et al., (2000) also observed a decrease in the EC for high xylene inlet concentrations and a decrease in both the RE and EC for high gas flow rates. A decrease in the RE after an increase of VOC OL was also observed by Yang et al., (2008) in a study focusing on the removal of ether on a rotating drum biofilter.

Along bioreactor operation, from all the individual VOC, 1-methoxy-2-propanol was detected at higher concentrations, both in the liquid medium and in the outlet stream (Fig. 2a), indicating that this compound is particularly difficult to biodegrade, especially at high OLs $\left(>100 \mathrm{~g} \mathrm{~h}^{-1} \mathrm{~m}^{-3}\right)$. The difficulty in the biodegradation of 1-methoxy-2-propanol has already been reported by Granström et al., (2002) during a chemostat experiment for the treatment of VOCs derived from a printing press. In that study, 1-metoxy-2-propanol, supplied at inflow concentrations between 60 and $190 \mathrm{~g} \mathrm{~m}^{-3}$, was one of the few compounds that was not completely removed in the chemostat, being the most difficult compound to biodegrade by the two yeast strains studied (Candida guilliermondii and Saccharomyces cerevisiae).

Along the SGB operation, the higher biodegradation performances were obtained for the compounds toluene and butylacetate (Fig. 3d and e, respectively). The RE of toluene obtained in the present study was similar to that reported by Neal and Loehr (2000) during a study comparing the performance of compost biofilters and suspended-growth reactors for the removal of that compound from gaseous streams. The maximum toluene EC achieved in the present study was $42 \mathrm{~g} \mathrm{~h}^{-1} \mathrm{~m}^{-3}$, being slightly below of that reported by Delhoménie et al., (2002) $\left(55 \mathrm{~g} \mathrm{~h}^{-1} \mathrm{~m}^{-3}\right)$ during the operation of a new compost-based biofilter for the treatment of toluene. Qi and Moe (2006) reported a study involving the treatment of a paint solvent mixture with biofilters and observed that the removal of toluene was more efficient when other compounds, like ethyl acetate or ketones, were absent. The authors attributed this effect to substrate inhibition or catabolic repression, a phenomenon which was not assessed in the experiments here reported.

Concerning butylacetate, REs of ca $100 \%$ were always obtained along the SGB operation (Fig. 2e). Baltrenas and Vaiskunaite (2003) performed an experiment with a biofilter to treat butylacetate, butanol and xylene and observed that with an increase in the concentrations of these organic compounds (from 0.030 to $0.10 \mathrm{~g} \mathrm{~m}^{-3}$ ), their biological RE decreased. In the present study, this was not observed for a range of butylacetate inlet concentrations between 0.0010 and $0.35 \mathrm{~g} \mathrm{~m}^{-3}$.

The concentration of the biomass suspended in the bioreactor culture medium was analysed along the SGB operation. The concentration of the suspended biomass varied significantly during the SGB operation (data not shown), which may have been partly attributed to biofilm formation observed frequently in the reactor walls, probably as defence mechanisms, especially during high VOC concentration exposure.

In conclusion, the results obtained in this study emphasize the robustness of SGBs, when exposed to dynamic treatment conditions. The fact that SGBs rely on suspended biomass for VOCs treatment, constitutes an important advantage of these systems, 
as clogging of VPBs treating gaseous emissions containing VOCs is often observed, leading to unoperational periods that can range from several weeks to over six months (Okkerse et al., 1999). Furthermore, these systems are able to maintain for long periods efficient degrading microbial cultures, contributing to the long term operational stability and efficiency of these reactors.

\section{Concluisions}

A microbial consortium able to degrade the main VOCs typical of a gaseous emission of a leather industrial plant was successfully enriched. A laboratory-scale SGB treating such gaseous emissions was successfully operated - up to $1.8 \times 10^{2} \mathrm{gh}^{-1} \mathrm{~m}^{-3}$ of overall VOCs were removed. High treatment performance for toluene and butylacetate was always obtained, but 1-methoxy-2-propanol presented higher recalcitrance to biodegradation. Overall, the recirculation of the outlet gas stream was shown to improve VOCs removal, with clearer influence under higher OLs, when the performance of the SGB was superior. The SGB was able to respond actively to dynamic treatment scenarios, particularly night and weekend shutdown periods.

\section{Acknowledgements}

M.F. Carvalho wishes to acknowledge a research grant from Fundação para a Ciência e Tecnologia (FCT), Portugal (SFRH/ BPD/14281/2003) and Fundo Social Europeu (III Quadro Comunitário de Apoio). This work was supported by the European LIFE program - SoNatura LIFE03 ENV/P/000521.

\section{References}

Baltrenas, P., Vaiskunaite, R., 2003. Volatile organic compounds elimination in an activated pine-charge of a biofilter using cultivated associations of natural microorganisms. In: Global Network of Environmental Science and Technology and Department of Environmental Studies of the University of the Aegean, 8th International Conference on Environmental Science and Technology. Lemnos island, Greece 8-10 September, 2003.

Baltzis, B., 1998. Biofiltration of VOC vapors. In: Lewandowski, G., DeFilippi, L. (Eds.), Biological Treatment of Hazardous Wastes. Wiley-Interscience, USA, pp. 119-150.

Bastos, F., Castro, P., Ferreira Jorge, R., 2003. Biological treatment of a contaminated gaseous emission from a paint and varnish plant - from laboratory studies to pilot-scale operation. J. Chem. Technol. Biot. 78, 1201-1207.

Bielefeldt, A., Stensel, H., 1998. BTEX-contaminated gas treatment in a shallow, sparged, suspended-growth bioreactor. Bioremed. J. 1, 241-254.

BREF - European Commission, Institute for Prospective Technological Studies, 2003a. Integrated Pollution Prevention and Control: Reference Document on Best Available Techniques in the Large Volume Organic Chemical Industry. Seville. <http://eippcb.jrc.es/pages/FActivities.htm>.

BREF - European Commission, Institute for Prospective Technological Studies, 2003b. Integrated Pollution Prevention and Control: Reference Document on Best Available Techniques in Common Waste Water and Waste Gas Treatment/ Management Systems in the Chemical Sector. Seville. <http://eippcb.jrc.es/ pages/FActivities.htm>.

BREF - European Commission, Institute for Prospective Technological Studies, 2003c. Integrated Pollution Prevention and Control: Reference Document on
Best Available Techniques for the Tanning of Hides and Skins. Seville. <http:// eippcb.jrc.es/pages/FActivities.htm>.

Caldeira, M., Heald, S.C., Carvalho, M.F., Bull, A.T., Vasconcelos, I., Castro, P.M.L., 1999. 4-Chlorophenol degradation by a bacterial consortium: development of a granular activated carbon biofilm reactor. Appl. Microbiol. Biot. 52, 722-729.

Council Directive 1999/13/EC of 11 March 1999 on the limitation of emissions of volatile organic compounds due to the use of organic solvents in certain activities and installations. Official Journal of the European Communities. L 85/1-22.

Council Directive 2004/42/EC of 21 April 2004 on the limitation of emissions of volatile organic compounds due to the use of organic solvents in certain paints and varnish and vehicle refinishing products and amending directive 1999/13/EC Official Journal of the European Communities. L 143/87-96.

Delhoménie, M.-C., Bibeau, L., Bredin, N., Sébastien, R., Broussau, S., Brzezinski, R. Kugelmass, J.L., Heitz, M., 2002. Biofiltration of air contaminated with toluene on a compost-based bed. Adv. Environ. Res. 6, 239-254.

Deshusses, M., Hamer, G., Dunn, I., 1995. Behavior of biofilters for waste air biotreatment. 2. Experimental evaluation of a dynamic model. Environ. Sci. Technol. 29, 1059-1068.

Ferreira Jorge, R., Livingston, A., 2000a. Microbial dynamics in an extractive membrane bioreactor exposed to an alternating sequence of organic compounds. Biotechnol. Bioeng. 70, 313-322.

Ferreira Jorge, R., Livingston, A., 2000b. Biological treatment of an alternating source of organic compounds in a single tube extractive membrane bioreactor. Biotechnol. Bioeng. 75, 1174-1182.

Goodal, J., Thomas, S., Spain, J., Peretti, S., 1998. Operation of mixed culture immobilized cell reactors for the metabolism of meta- and para-nitrobenzoate by Comamonas sp JS46 and Comamonas sp JS47. Biotechnol. Bioeng. 59, 21-27.

Granström, T., Lindberg, P., Nummela, J., Jokela, J., Leisola, M., 2002. Biodegradation of VOCs from printing press air by on-site pilot plant bioscrubber and laboratory scale continuous yeast cultures. Biodegradation 13, 155-162.

Jorio, H., Bibeau, L., Viel, G., Heitz, M., 2000. Effects of gas flow rate and inlet concentration on xylene vapors biofiltration performance. Chem. Eng. Sci. 76, 209-221.

Kennes, C., Thalasso, F., 1998. Waste gas biotreatment technology. J. Chem. Technol Biot. 72, 303-319.

Kirchner, K., Gossen, C., Rehm, H., 1991. Purification of exhaust air containing organic pollutants in a trickle-bed bioreactor. Appl. Microbiol. Biot. 35, 396-400.

Koutinas, M., Baptista, I., Meniconi, A., Peeva, L.G., Castro, P.M.L., Livingston, A.G., 2007. The use of an oil-absorber-bioscrubber system during biodegradation of sequentially alternating loadings of 1,2-dichloroethane and fluorobenzene in a waste gas. Chem. Eng. Sci. 62, 5989-6001.

Neal, A., Loehr, R., 2000. Use of biofilters and suspended-growth reactors to treat VOCs. Waste Manage. 20, 59-68.

Okkerse, W.J.H., Ottengraf, S.P.P., Osinga-Kuipers, B., Okkerse, M., 1999. Biomass accumulation and clogging in biotrickling filters for waste gas treatment. Evaluation of a dynamic model using dichloromethane as a model pollutant. Biotechnol. Bioeng. 63, 418-430.

Oliveira, T., Livingston, A., 2003. Bioscrubbing of waste gas - substrate absorber to avoid instability induced by inhibition kinetics. Biotechnol. Bioeng. 84, 552563.

Pedersen, A., Moller, S., Molin, S., Arvin, E., 1997. Activity of toluene-degrading Pseudomonas putida in the early growth phase of a biofilm for waste gas treatment Biotechnol. Bioeng. 54, 131-141.

Qi, B., Moe, W., 2006. Performance of low pH biofilters treating a paint solvent mixture: continuous and intermittent loading. J. Hazard. Mater. 135, 303310.

Rene, E., Murthy, D., Swaminathan, T., 2005. Performance evaluation of a compost biofilter treating toluene vapours. Process Biochem. 40, 2771-2779.

Smith, F., Sorial, M., Suidan, M., Breen, A., Biswas, P., 1996. Development of two biomass control strategies for extended, stable operation of highly efficient biofilters with high toluene loadings. Environ. Sci. Technol. 30, 1744-1751.

Speitel, G., McLay, D., 1993. Biofilm reactor for treatment of gas streams containing chlorinated solvents. J. Environ. Eng. - ASCE 119, 658-678.

Yang, C., Chen, H., Zeng, G., Zhu, X., Suidan, M.T., 2008. Performance of rotating drum biofilter for volatile organic compound removal at high organic loading rates. J. Environ. Sci. China 20, 285-290. 